\title{
Comparative analysis between three forms of application of transcutaneous electrical nerve stimulation and its effect in college students with non-specific low back pain
}

\author{
Análise comparativa de três formas de aplicação de estimulação elétrica nervosa transcutânea \\ e seu efeito na redução da dor em universitários com lombalgia inespecífica
}

Carla Maria Verruch ${ }^{1}$, Andersom Ricardo Fréz², Gladson Ricardo Flor Bertolini ${ }^{1}$

DOI 10.5935/2595-0118.20190024

\section{ABSTRACT}

BACKGROUND AND OBJECTIVES: There are a variety of ways to apply the transcutaneous electrical nerve stimulation (TENS) without an established way that provides better results in the treatment of nonspecific low back pain. The objective of this study was to evaluate which application of TENS has a better effect on the immediate reduction of the intensity of spontaneous and provoked pain in college students with nonspecific low back pain.

METHODS: Quantitative, randomized and cross-sectional study. Twenty young individuals were divided into four groups and received a different intervention per week, totaling four weeks. The groups were Conventional TENS with the frequency of $100 \mathrm{~Hz}$, a pulse duration of $200 \mu$ s; TENS with frequency and intensity variation with frequency variation and automatic pulse duration, TENS Burst with frequency modulated at $2 \mathrm{~Hz}$, pulse duration of $250 \mu$ s; and placebo in which the subjects underwent a pacing protocol with no tingling sensation or muscle contraction. All sessions had a total application time of 20 minutes. They were evaluated for spontaneous pain through the application of the visual analog scale (VAS), and pain provoked by the algometer and cold pain through the application of solid ice directly to the skin, and VAS for the intensity of cold pain, all performed before and after each application of the electrotherapy.

RESULTS: Only the visual analog scale of spontaneous pain showed significant results $(\mathrm{p}<0.05)$ when compared intragroups, in the three applied currents.

CONCLUSION: The three forms used in the present study were able to reduce spontaneous pain after the intervention by electrostimulation.

Carla Maria Verruch - (Dhttps://orcid.org/0000-0002-5072-407X;

Andersom Ricardo Fréz - Dhttps://orcid.org/0000-0001-6085-1382;

Gladson Ricardo Flor Bertolini - (Dhttps://orcid.org/0000-0003-0565-2019.

1. Universidade Estadual do Oeste do Paraná, Cascavel, PR, Brasil.

2. Universidade Estadual do Centro Oeste, Guarapuava, PR, Brasil.

Submitted on December 11, 2018.

Accepted for publication on March 06, 2019.

Conflict of interests: none - Sponsoring sources: none.

Correspondence to:

Rua Universitária, 2069 - Jardim Universitário

85819-110 Cascavel, PR, Brasil.

E-mail: gladsonricardo@gmail.com

(C) Sociedade Brasileira para o Estudo da Dor
Keywords: Analgesia, Low back pain, Transcutaneous electrical nerve stimulation.

\section{RESUMO}

JUSTIFICATIVA E OBJETIVOS: Há uma variedade de formas de aplicação de estimulação elétrica nervosa transcutânea (TENS), sem que haja uma forma definida com melhores resultados no tratamento para a dor lombar inespecífica. O objetivo deste estudo foi avaliar qual aplicação de TENS tem melhor efeito sobre a reduçáo imediata da intensidade da dor espontânea e provocada, em universitários com lombalgia inespecífica.

MÉTODOS: Estudo quantitativo, aleatorizado e cruzado. Vinte indivíduos jovens foram distribuídos em quatro grupos e realizaram uma intervençáo diferente por semana, totalizando quatro semanas. Grupos TENS convencional com frequência de $100 \mathrm{~Hz}$, duração de pulso de $200 \mu$ s; TENS variação de frequência e intensidade com variação de frequência e duraçáo de pulso automática, TENS Burst com frequência modulada em $2 \mathrm{~Hz}$, duração de pulso $250 \mu$ s; e placebo em que os indivíduos foram submetidos a um protocolo de estimulação sem nenhuma sensação de formigamento ou contração muscular. Todas as sessões tiveram uma aplicação total de 20 minutos. Foram avaliados pela dor espontânea por meio da aplicação da escala analógica visual (EAV), e dor provocada pelo dolorímetro e dor ao frio por meio da aplicação de gelo sólido diretamente na pele, e EAV para intensidade de dor ao frio, todos realizados antes e após cada aplicação de eletroterapia.

RESULTADOS: Apenas a escala analógica visual de dor espontânea apresentou resultados significativos $(\mathrm{p}<0,05)$ quando comparado intragrupos, nas três correntes aplicadas.

CONCLUSÂO: As três formas utilizadas no presente estudo foram capazes de reduzir a dor espontânea após a intervenção por eletroestimulação.

Descritores: Analgesia, Dor lombar, Estimulação elétrica nervosa transcutânea.

\section{INTRODUCTION}

Low back pain is defined as pain or discomfort, located in the dorsal area between the last ribs and the gluteal folds, and may or may not present referred pain in the lower limbs. It represents a substantial economic burden for people in general, requiring 
national and international measures aimed at prevention and reduction of treatment costs ${ }^{1,2}$.

Diagnostic screening, depending on the degree of specificity, can be classified in two ways: specific and nonspecific low back pain (LBP). Nonspecific LBP is characterized as a pain that is not attributed to a previous disease/injury, such as infections, tumors, fractures, structural deformities, root syndrome, among others ${ }^{3}$. Although not having a primary cause, nonspecific LBP has many risk factors related to childhood and adolescence, such as excessive heavy backpacks, improper posture, and ergonomics of school desks ${ }^{4}$. Although the first cases are linked to puberty, the occurrence of low back pain in students and healthcare professionals is possibly related to the amount of academic and professional tasks, coupled with inadequate furniture and physical requirements ${ }^{5}$.

The first choice to treat LBP is always conservative, as it is effective in reducing pain. The use of pharmacological therapy, application of local heat and electrostimulation, besides being less invasive, costs less than the surgical treatment ${ }^{6}$. Transcutaneous electrical nerve stimulation (TENS) is considered a good treatment option for LBP because it is a non-invasive, non-pharmacological technique and responsible for activating afferent inhibitory neurons using electrodes on the skin surface ${ }^{7}$.

This therapy can be performed in different clinical settings. When applied with a high frequency, such as conventional TENS therapy, it has an A $\beta$ fiber depolarization effect, capable of activating interneurons that are responsible for inhibiting the conduction of pain by the $A \delta$ and $C$ fibers ${ }^{8}$. When applied at low frequencies, such as the TENS burst therapy characterized by strong stimuli, it depolarizes the fast pain $(\mathrm{A} \delta)$ and slow pain $(C)$ fibers, which through the activation of pain modulating mechanisms located in the region of puns and bulb can produce descending analgesia. Both applications are effective in reducing pain through the release of endogenous opioids ${ }^{910}$. Another form of TENS application is the one in which there is an automatic variable intensity frequency (VIF), as well as changes in the pulse length, presenting combined effects of the therapies with high and low frequencies, aiming mainly to hinder the accommodation phenomenon ${ }^{11}$.

To evaluate the effectiveness of different types of electrostimulation, different pain stimuli can be measured, such as cold, analyzing intensity and pain threshold, as well as the pressure pain threshold. Such stimuli are responsible for pain reactions and can occur by depolarization of $\mathrm{C}$ and $\mathrm{A} \delta$ fibers ${ }^{8,12}$.

There are many ways of applying TENS, without having a definite way to obtain better treatment results for nonspecific LBP.

Thus, the objective of the present study was to evaluate which kind of application of TENS has a better effect on the immediate reduction of the intensity of spontaneous and provoked pain, in college students with nonspecific LBP.

\section{METHODS}

The present study is characterized as quantitative, randomized and crossed-sectional. Data collection was performed at the
Physical Rehabilitation Center (CRF) - UNIOESTE and all participants signed the Free and Informed Consent Form (FICT). Eight male and 12 female volunteers participated in the study, aged from 18 to 27 years old (mean of $20.78 \pm 2.65$ years), weight $70.25 \pm 14.97 \mathrm{~kg}$, height $1.68 \pm 0.07 \mathrm{~m}$, and body mass index (BMI) of 24.53 \pm 4.58 , who presented nonspecific LBP for at least three months, and were included only those who were not performing any type of treatment. The exclusion criteria were contraindications for the use of electrostimulation of any kind, the use of a pacemaker or a metal implant.

Data collection lasted for four weeks, and all 20 subjects were submitted, crossed-sectional, to the four sessions, once a week, in groups previously selected by lot, and the individual had to go through the four intervention groups, not being allowed to repeat the type of current application.

The groups were: conventional TENS (CTG), burst TENS (BTG), VIF TENS (VTG) and placebo (PG).

It was used the visual analog scale (VAS) to quantify the intensity of spontaneous pain, which presents values from zero to 10 , where zero refers to no discomfort and 10 refers to the maximum bearable discomfort, being measured before the other evaluations ${ }^{13}$. A pain stimulus under pressure and $\operatorname{cold}^{14}$ was applied to evaluate the provoked pain threshold. First, the Kratos algometer was used, capable of producing a pressure of up to $50 \mathrm{Kgf}$. All procedures were explained to the volunteers, and the pressure was applied in the low back area, always bilaterally, $2 \mathrm{~cm}$ lateral to the spinous process of the vertebrae referred to as being more sensitive to palpation. The moment the pressure pain threshold was reached, the algometer was removed, and the value of the highest pressure exerted was written down. To evaluate the pain for cold, ice was applied directly to the skin in the low back area, at the same place of the pressure evaluation, writing down the time in seconds that the volunteer took to feel the pain stimulus, that is, the threshold of pain for cold. Besides, the VAS was also used to quantify the intensity of pain for cold after contact with the ice. All evaluations were performed before the application of the therapy and repeated at the end of the session, including in the PG.

After the pain evaluation, the electrostimulation therapy was applied using the Ibramed Neurodyn II device, drawn for the participant in each intervention day. In all groups, the individual was positioned in the prone position, with the electrodes arranged longitudinally on the low back area (L1-L5). The gel was applied to create the interface for current transmission, and the electrodes were fixed with adhesive tape. Finally, the device was switched on following the parameters of each protocol. In the three types of current application, whenever there was accommodation, the intensity was increased, according to the patient's report. The total duration of therapy was 20 minutes in all groups ${ }^{14,15}$.

In the CTG, the subjects were submitted to the application of the current with a frequency of $100 \mathrm{~Hz}$, a pulse duration of $200 \mu$ s (microseconds), with comfortable amplitude, depending on the participant's threshold, without occurring motor stimulation. In the VTG, the current application used as parameter the frequency of 2 to $247 \mathrm{~Hz}$, a pulse duration of 50 to $500 \mu$ s and high amplitude, yet comfortable. And in BTG, the current was 
applied with frequency modulated at $2 \mathrm{~Hz}$, a pulse duration of $250 \mu$ s, with sufficient amplitude to generate a rhythmic muscle contraction sensation, associated with tingling, yet comfortable. At the PG, the volunteers did not receive electrical stimulation, but at the beginning of the intervention, the evaluator explained that they were being submitted to a protocol below the sensory threshold, in which they would not have any sensation of tingling or muscular contraction. The electrodes were placed, and the device switched on, however, there was no electric current transmission.

All procedures followed the ethical criteria required for work in humans, with prior approval by the Research Ethics Committee of the State University of the Oeste do Paraná (UNIOESTE), under number: 2.588 .536 of 2018 .

\section{Statistical analysis}

For this size of the sample used, with a difference to be detected and a standard deviation of 2.5, and a significance level of

Table 1. Data on mean and standard deviation for the groups when evaluated by the visual analog scale, before and after treatment and value of difference and $p$ between evaluations

\begin{tabular}{lccc}
\hline Groups & Initial evaluation & Final evaluation & Effect size \\
\hline CTG & $5.15 \pm 2.64$ & $2.4 \pm 1.95^{*}$ & -1.21 \\
VTG & $5.15 \pm 2.45$ & $2.65 \pm 1.69 *$ & -1.20 \\
BTG & $4.95 \pm 2.66$ & $2.4 \pm 1.95^{*}$ & -1.08 \\
PG & $4.8 \pm 2.76$ & $3.15 \pm 2.66$ & 0.60
\end{tabular}

$\mathrm{CTG}=$ conventional TENS group; VTG = VIF TENS group; BTG = burst TENS group; $P G=$ placebo group; ${ }^{*}$ significant value of $p(5 \%)$ when compared to the initial evaluation.
$5 \%$, the calculated test power was $80 \%$ for ANOVA evaluation using the software Bioestat 5.0. The results were analyzed by descriptive and inferential statistics, and there was normality for the daily VAS (Shapiro-Wilk). Thus, one-way ANOVA was used with an evaluation of the size of the Cohen effect. For the other variables, the Friedman test was used for non-parametric data. The accepted level of significance was 5\% ( $<<0.05)$.

\section{RESULTS}

Table 1 shows the assessment of the spontaneous pain intensity by VAS, before and after the treatment with a $\mathrm{p}<0.0001$, and when compared between the groups there was no significant difference. When compared with PG, the effect sizes were considered small for the initial evaluation (conventional - 0.13, VIF 0.13 , and burst 0.05 ), as well as for the final evaluation (conventional 0.32; VIF -0.22 and burst -0.32).

In the evaluation of pain by pressure stimulus with the algometer, there was no significant difference between initial and final evaluations intra-group or between the different ways of the current application (Fr: 7.1 and $\mathrm{p}=0.4185$ ), as shown in table 2 .

For the evaluation of the threshold of pain for cold pain, there were no significant results in the intra-group analysis in both tests (Fr: 10.4 and $\mathrm{p}=0.1666)$ and (Fr: 32.4 and $\mathrm{p}<0.0001)$, respectively. Yet, the VAS presented a significant p-value, which occurred when the different evaluations of the different treatment groups were compared, not happening between the evaluations in the same group or at similar moments in the four groups. Table 3 shows the other data.

Table 2. Presentation of the data in the median, first and third quartile, and the sum of ranks for the groups when the threshold of pressure pain algometer (gf) was evaluated before and after treatment

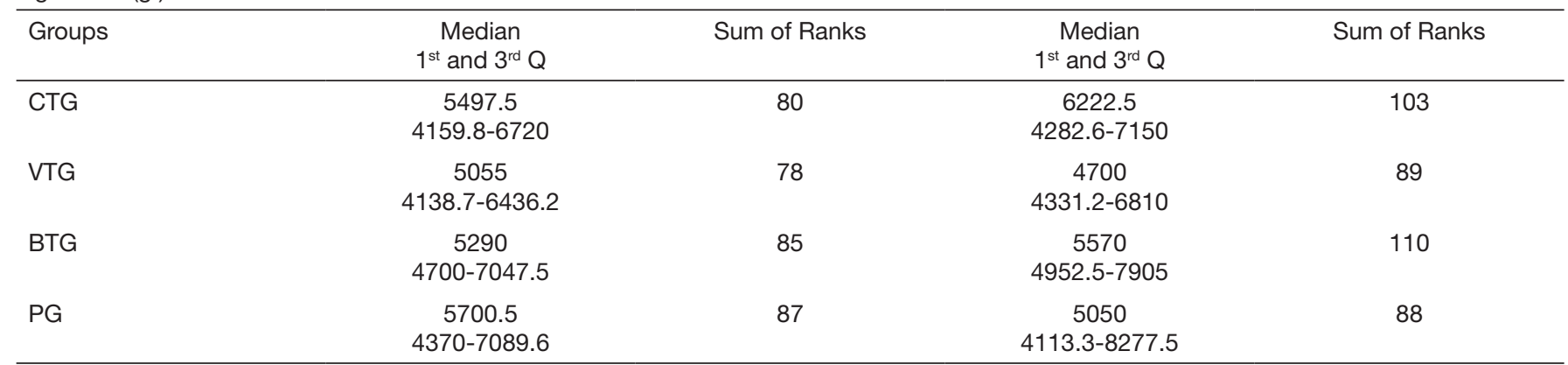

$\overline{\mathrm{CTG}}=$ conventional TENS group; VTG = VIF TENS group; $\mathrm{BTG}$ = burst TENS group; PG = placebo group.

Table 3. Presentation of the data in the median, first and third quartile, and the sum of ranks for the groups when assessing the pain threshold of cold pain (seconds) and the visual analog scale for cold pain, before and after treatment

\begin{tabular}{|c|c|c|c|c|c|}
\hline & Groups & $\begin{array}{c}\text { Median } \\
1^{\text {st }} \text { and } 3^{\text {rd }} Q\end{array}$ & Sum of Ranks & $\begin{array}{c}\text { Median } \\
1^{\text {st }} \text { and } 3^{\text {rd }} Q\end{array}$ & Sum of Ranks \\
\hline \multirow{4}{*}{ Pain threshold to cold (seconds) } & CTG & $\begin{array}{c}28.2 \\
17.8-64.5\end{array}$ & 79.5 & $\begin{array}{c}48.5 \\
18.2-160.8\end{array}$ & 103.5 \\
\hline & VTG & $\begin{array}{c}24.2 \\
14.3-70.5\end{array}$ & 75 & $\begin{array}{c}33 \\
17.7-152\end{array}$ & 104.5 \\
\hline & BTG & $\begin{array}{c}34.5 \\
15.7-65.3\end{array}$ & 87 & $\begin{array}{c}41.5 \\
19.7-104.3\end{array}$ & 108.5 \\
\hline & $P G$ & $\begin{array}{c}33 \\
15.6-81.3\end{array}$ & 79 & $\begin{array}{c}32.5 \\
14.8-90.3\end{array}$ & 83 \\
\hline
\end{tabular}


Table 3. Presentation of the data in the median, first and third quartile, and the sum of ranks for the groups when assessing the pain threshold of cold pain (seconds) and the visual analog scale for cold pain, before and after treatment - continuation

\begin{tabular}{|c|c|c|c|c|c|}
\hline & Groups & $\begin{array}{c}\text { Median } \\
1^{\text {st }} \text { and } 3^{\text {rd }} Q\end{array}$ & Sum of Ranks & $\begin{array}{c}\text { Median } \\
1^{\text {st }} \text { and } 3^{\text {rd }} Q\end{array}$ & Sum of Ranks \\
\hline \multirow{3}{*}{ Visual analog pain scale to cold } & CTG & $\begin{array}{c}5 \\
3-6\end{array}$ & 100.5 & $\begin{array}{c}3 \\
2-4\end{array}$ & 57.5 \\
\hline & VTG & $\begin{array}{c}5 \\
4-6\end{array}$ & 113.5 & $\begin{array}{c}4 \\
3-4\end{array}$ & 68 \\
\hline & BTG & $\begin{array}{c}5 \\
4-6.5\end{array}$ & 126 & $\begin{array}{c}3.5 \\
3-6\end{array}$ & 80 \\
\hline
\end{tabular}

$\overline{\mathrm{CTG}}=$ conventional TENS group; $\mathrm{VTG}=\mathrm{VIF}$ TENS group; $\mathrm{BTG}=$ burst TENS group; $\mathrm{PG}=$ placebo group.

\section{DISCUSSION}

Three types of application of TENS therapy (conventional, burst and VIF) were tested for the analysis of the reduction of spontaneous and induced pain by pressure and thermal stimuli. Since all three were effective in reducing spontaneous pain, no significant results were found to indicate the best for the treatment of low back pain.

Several studies have shown that the use of TENS to treat LBP is a viable option, with significant evidence of its effectiveness, both for acute and chronic pain and with few contraindications for the patient ${ }^{7,16,17}$.

The reduction of spontaneous pain evaluated by the VAS had a significant result for the three ways of TENS application, which reproduces the results found in a study ${ }^{18}$ that used a model of low frequency $(20 \mathrm{~Hz}, 220 \mu \mathrm{s})$ TENS and interferential current in the low back area. It also reproduced another study ${ }^{19}$ which evaluated the effectiveness of TENS in high and low frequencies. However, one study has shown that for the reduction of post-cesarean pain intensity, the high frequency would be better ${ }^{20}$.

In a systematic review of 29 studies on the efficacy of conventional TENS, 16 had positive results in pain reduction. When evaluated specifically for pressure pain, 8 studies have proved their efficacy, while 4 have not shown significant results. As for the pain caused by cold, there is moderate evidence regarding its effectiveness. There are three low-quality studies with positive results, and one low-quality study with negative results for this type of stimulus ${ }^{21}$.

A study comparing the application of TENS in low and high frequencies, as well as the combined approach, emphasized that the use of TENS with variable frequency and intensity, such as VIF, reduces the occurrence of the development of current tolerance and can produce a greater analgesic effect. However, this fact was not reproduced in the present study, due to the single application of each TENS intervention ${ }^{22}$.

The samples were composed of subjects of both genders, most women, which may be a limitation of this study. A previous study pointed out that there are differences in the pain threshold between men and women, mainly regarding pressure pain, which is the most sensitive to the differences of gender ${ }^{23}$. This corroborates the results of previous studies using TENS in the conventional mode $(100 \mathrm{~Hz}, 250 \mu \mathrm{s})$ and the high voltage polarized current $(100 \mathrm{~Hz}, 50 \mu \mathrm{s})$ and TENS therapy in different frequency configurations, both in the elbow area that did not obtain significant values in the evaluation of pressure pain after the treatment with analgesic currents ${ }^{15,24}$.

However, a comparative study between TENS therapy $(100 \mathrm{~Hz}, 40 \mu \mathrm{s})$ and its association with cryotherapy $(20 \mathrm{~min}-$ utes) was effective in increasing the pressure pain threshold in the forearm area in healthy individuals. However, the method used to apply the pressure algometer differed from the other studies, since it asked the participant to report when they felt pain proportional to level 3 of the VAS, which may be the cause of the uneven results ${ }^{25}$.

Regarding its efficacy in the reduction of cold-induced pain, there are differences in the results of a study ${ }^{26}$, which using TENS at the frequency of $10 \mathrm{~Hz}$ applied in acupuncture points was able to reduce the intensity of cold pain in the hand area. Another study ${ }^{27}$, which used the acupuncture mode $(10 \mathrm{~Hz}$ and $250 \mu \mathrm{s})$ to assess cold pain by the hand immersion method in cold water, did not obtain significant results. This data is in line with this study that used different parameters of TENS current application with the same purpose and did not find significance in the pain threshold supported in seconds, and pain intensity, quantified by the VAS.

\section{CONCLUSION}

The three ways of TENS application, conventional, VIF, and burst, were effective in the treatment of spontaneous pain since there was a significant numerical reduction in the VAS after the intervention. However, as none of the three ways of application has been excelled in the efficacy of pain reduction, further studies are needed to see if a similar result will be found when performed with a more extended protocol or with same-gender volunteers.

\section{REFERENCES}

1. Meucci RD, Linhares AO, Olmedo DW, Sobrinho Cousin EL, Duarte VM, Cesar JA. Dor lombar em adolescentes do semiárido: resultados de um censo populacional no município de Caracol (PI), Brasil. Ciên Saúde Coletiva. 2018;23(3):733-40.

2. Orelo RI, Ragasson CA, Lerner CE, Morais JC, Cossa JB, Krauczuk C. Efeito de um programa cinesioterapêutico de grupo, aliado à escola de postura, na lombalgia crônica. Fisioter Mov. 2013;26(2):389-94.

3. Rached RD, Rosa CD, Alfieri FM, Amaro SM, Nogueira B, Dotta L, et al. Lombalgia 
inespecífica crônica: reabilitação. Acta Fisiátr. 2012;19(2):99-113.

4. Furtado RN, Ribeiro LH, Abdo Bde A, Descio FJ, Martucci CE Jr, Serruya DC. [Nonspecific low back pain in young adults: associated risk factors]. Rev Bras Reumatol. 2014;54(5):371-7. Portuguese.

5. Alfieri FM, Oliveira NC, Santana IE, Ferreira KM, Pedro RD. Prevalência de dor lombar em universitários da saúde e sua relaçăo com estilo de vida e nível de atividade física. Rev Inspirar. 2016;11(4):27-31.

6. Santos JK, Gomes Júnior VF, Souza AS, Farias NS, Marques SS, Costa JM. Socio-demographic and physical-functional profile of low back pain patients assisted in Manaus-AM. Rev Dor. 2015;16(4):272-5.

7. Vance CG, Dailey DL, Rakel BA, Sluka KA. Using TENS for pain control: the state of the evidence. Pain Manag. 2014;4(3):197-209.

8. Mendell LM. Constructing and deconstructing the gate theory of pain. Pain. 2014;155(2):210-6.

9. Bergeron-Vézina K, Corriveau H, Martel M, Harvey MP, Léonard G. High- and low-frequency transcutaneous electrical nerve stimulation does not reduce experimental pain in elderly individuals. Pain. 2015;156(10):2093-9.

10. Johnson MI, Paley CA, Howe TE, Sluka KA. Transcutaneous electrical nerve stimulation for acute pain. Cochrane Database Syst Rev. 2015;(6):CD006142.

11. Thakur A, Sukumar S. Analgesic effects of modulated frequency transcutaneous electrical nerve stimulation in the relief of pain after abdominal surgery - a randomized controlled trial. Int J Health Sci Res. 2017;5(5):237-43.

12. Montenegro EJ, Almeida BG, Alencar GG, Siqueira GR, Maia JN, Andrade MA. Açăo das ondas curtas pulsada na dor aguda induzida pela hipotermia: um estudo piloto. Rev Bras Ci Mov. 2017;25(2):145-53.

13. Silva BC, Coracini CA, Lautenschleger C, Branco, Michelon MD, Bertolini GR. Aussie current in students with chronic neck pain: a randomized controlled trial. BrJP. 2018;1(3):202-6

14. Fiori A, Cescon CL, Galesky JD, Santos TA, Brancalhão RM, Bertolini GR. Comparison between bipolar and tetrapolar of the interferential current in nociceptive threshold, accommodation and pleasantness in healthy individuals. Eur J Physiother. 2014;16(4):201-5.

15. Gomes Ade O, Silvestre AC, Silva CF, Gomes MR, Bonfleur ML, Bertolini GR. Influence of different frequencies of transcutaneous electrical nerve stimulation on the threshold and pain intensity in young subjects. Einstein. 2014;12(3):318-22. English, Portuguese.
16. Santos I, Rodrigues AA, Martins AB, Faria WC. Avaliaçấo da efetividade da TENS e da eletroacupuntura na lombalgia. ConScientiae Saúde. 2008;7(4):519-24.

17. Dohnert MB, Bauer JP, Pavão TS. Study of the effectiveness of interferential current as compared to transcutaneous electrical nerve stimulation in reducing chronic low back pain. Rev Dor. 2015;16(1):27-31.

18. Facci LM, Nowotny JP, Tormem F, Trevisani VF. Effects of transcutaneous electrical nerve stimulation (TENS) and interferential currents (IFC) in patients with nonspecific chronic low back pain: randomized clinical trial. Sao Paulo Med J. 2011;129(4):206-16.

19. Chen C, Johnson MI. A comparison of transcutaneous electrical nerve stimulation (TENS) at 3 and 80 pulses per second on cold-pressor pain in healthy human participants. Clin Physiol Funct Imaging. 2010;30(4):260-8.

20. Lima LE, Lima AS, Rocha CM, Santos GF, Bezerra AJ, Hazime FA, et al. Estimulação elétrica nervosa transcutânea de alta e baixa frequência na intensidade da dor. Fisioter Pesq. 2014;21(3):243-8.

21. Claydon LS, Chesterton LS, Barlas P, Sim J. Dose-specific effects of transcutaneous electrical nerve stimulation (TENS) on experimental pain: a systematic review. Clin J Pain. 2011;27(7):635-47.

22. DeSantana JM, Walsh DM, Vance C, Rakel BA, Sluka KA. Effectiveness of transcutaneous electrical nerve stimulation for treatment of hyperalgesia and pain. Curr Rheumatol Rep. 2008;10(6):492-9.

23. Palmeira CC, Ashmawi HA, Posso Ide P. [Sex and pain perception and analgesia]. Rev Bras Anestesiol. 2011;61(6):814-28. English, Multiple languages.

24. Zegalo BP, Silva CF, Mariani L, Jurkevicz R, Karvat J, Carvalho AR, et al. Efeitos da estimulação elétrica nervosa transcutânea e da corrente de alta voltagem em indivíduos saudáveis. Revista Saúde e Pesquisa (Maringá). 2016;9(2):291-7.

25. Maciel LF, Ferreira JJ, Santos HH, Andrade PR. Efeitos da estimulaçấo elétrica nervosa transcutânea e da crioterapia sobre o limiar de dor induzida por pressão. Fisioter Pesq. 2014;21(3):249-56.

26. Montenegro EJ, Alencar GG, Siqueira GR, Guerino MR, Maia JN, Oliveira DA. Effect of low frequency transcutaneous electrical nerve stimulation of TE5 (waiguan) and PC6 (neiguan) acupoints on cold-induced pain. J Phys Ther Sci. 2016;28(1):76-81.

27. Cheroto AC, Yamada EF. Efeito da TENS e da corrente interferencial na dor induzida pelo frio. Rev Bras Reabilitação e Atividade Física (Vitória). 2014;3(1):7-13. 